SHS Web of Conferences 12,01058 (2014)

DOI: $10.1051 /$ shsconf $/ 20141201058$

(C) Owned by the authors, published by EDP Sciences, 2014

\title{
Rail travel: Conceptualizing a study on slow tourism approaches in sustaining rural development
}

\author{
Farah Atiqah Mohamad Noor ${ }^{1}$, Vikneswaran Nair ${ }^{2}$, Paolo Mura ${ }^{3}$ \\ ${ }^{1,2,3}$ School of Hospitality, Tourism and Culinary Arts, Taylor's University, 47500 Subang Jaya, \\ Selangor Darul Ehsan, Malaysia
}

\begin{abstract}
Rail transportation in Peninsular Malaysia is a popular transportation mode for locals to return to their hometown but is not frequently used as the mode of transport when travelling for holidays. Rural towns in Peninsular Malaysia have immense opportunity to be promoted as a popular tourism destination without the need of intense modern development. Using train rather than taking a car or a bus would endorse the concept of slowness during travel enabling tourists to enjoy the time taken to travel rather than rushing to travel to a destination. Encouragement of travelling by rail to the rural towns will enable improved utilization of the existing rail network and further uplift the travel appeal to rural towns in Peninsular Malaysia. In order to promote the concept of slow tourism that would benefit the rural towns' sustainability, the perception of tourists on travelling slowly by train should first be understood and taken for consideration. A qualitative methodology of in depth interviews with domestic and international tourists whom have travel on trains to the rural towns will be conducted.
\end{abstract}

\section{Introduction}

Slow tourism is relatively a new concept and has only been studied over the last 30 years in comparison with other types of tourism that has been studied for over a century ago. Many researches that have been conducted on this topic spans on the likes of definition [1], Savelli's types of slow tourist [2] and how slow tourism works in a popular tourist destination such as Caribbean [3] . However, there are very few researches that are being conducted on the perception and mind set of tourists of a country to pursue slow tourism.

Rail sometimes serve mainly as a transportation corridor connecting rural areas, or urban settings and green strips and other times become the recreational ground for domestic and international tourists [4]. Railway lines in Peninsular Malaysia have existed for more than a century ago since the colonial times. Currently, the railway lines serve as an intercity transport between the bigger towns and rural towns of Peninsular Malaysia. Visiting rural towns in Peninsular Malaysia has been confined to travelling via a car and buses especially for the locals. Most of the locals only use intercity train when they are returning to their hometown but not travelling for holiday purposes. 
There are numerous rural towns along the intercity train route in Peninsular Malaysia which offers the opportunity for rural tourism to be explored. This opportunity can be beneficial to develop rural towns as a growing tourism destination while maintaining the charm and uniqueness of a quaint town. The main idea for using rail travel as a gateway to rural tourism experience is adapting the concept of the slowness of travel that has been forgotten by many tourists nowadays.

The main purpose of conducting this study is to understand the willingness of tourists to travel slowly by choosing a transportation mode such as the intercity train to travel to rural towns in Peninsular Malaysia. The researcher wants to highlight rail travel as one of the attraction of the rural holiday experience rather than the full experience of the rural destination itself. In this study, the slow concept is highly regarding the transport mode chosen while on holiday. Comparing to the airplane, train is a more convenient and a practical transport to choose, especially for distances of less than 800 kilometres [2].

Taking Kuala Lumpur as the starting point to the rural towns for example, certainly the total area travelled from Kuala Lumpur to any of the rural towns will be lesser than the actual 700 miles (1126 $\mathrm{km}$ ) length of the whole Peninsular Malaysia [5]. Aside from that, the environmental and sociocultural features of rural towns in Peninsular Malaysia can be feasibly preserved by focusing on promoting these towns through existing intercity rail transportation. Not to mention, this study can encourage tourists to feel that it is good to take their time during travelling to rural towns because only by slower pace that they get to appreciate the cultural heritage of Malaysians.

A rural town in the context of Peninsular Malaysia is the agricultural land of natural resource sector companies, especially in the plantation and mining sectors; with a low level of urbanization and having natural resource-based industries as the main income source [6]. In order to promote slow tourism via rail to the rural towns, the researcher would like to conceptualize this study to understand the possibility for rail travel to assist the development of rural towns throughout Peninsular Malaysia. Before this concept is rationalized, we must first realize the perception of a small number of tourists that travel using train to these rural towns along the intercity train route and also the locals who never travel with train for holiday purposes. Peninsular Malaysia is chosen in order to encourage the transfer of tourist displacement not just concentrated in Klang Valley but also in rural towns throughout Peninsular Malaysia.

\section{Literature Review}

Slow tourism concept derived from the Slow Food Italy as pioneered by Carlo Petrini in the 1980s. As a non-profit, member-supported, eco-gastronomic organization, The Slow Food movement established in 1989 aimed to decrease the eating trend of fast food and fast life as well as bringing back the local food traditions and people's interest in the food they eat, its origins and how our food options affect the rest of the world [7].

Slow City (CittaSlow) movement is a non-profit organization that appear from the principles of Slow Food movement which further emphasized the need to adopt the slowness of life against the fast pace of 21st century. Principles of the CittaSlow movement includes to maintain a calm and less polluted physical environments, conserve local aesthetic traditions and foster the crafts, cuisine and produce of the locals [8].

The slow concept has been further strengthened by Carl Honore and his hugely successful book, In Praise of Slowness where he talked about the current generation obsession with everything fast and trying to encourage the return to the original idea of slowness in life [9]. Using technology to create healthier environments, making citizens aware of the value of more leisurely life rhythms and sharing their experience to seek administrative solutions for better living are also the pledges of Slow City movement [8]. 
Through both Slow Food and Slow City movement, the birth of a new type of tourism called slow tourism has slowly encapsulated the belief that domestic, regional and international tourism could adapt to the approach of slow travel through transportation used, cuisine experienced and changing perception of travel values. Slow tourism puts itself in the alternative tourism genre by adopting 'soft growth' concept where advancing development (quality) instead of promoting physical growth (quantity) is emphasized [3].

Therefore, slow tourism is a type of tourism promoting equitable socioeconomics benefits to local communities, curbs environmental pressures, and fulfils the rising responsible tourism demand favoured by a more consciously motivated group of travellers [3]. Articles on slow tourism has been contributed by other authors such as authors of Slow Travel and Tourism [10], as well as Conway and Timms [3] whom studied slow tourism and applying it as the alternative tourism activity in Caribbean Islands. The table highlights certain dimensions of slow tourism based on a conceptual framework constructed by Lumsdon and McGrath [1]:

Table 1. Dimensions in Slow Tourism (Lumsdon \& McGrath, 2011)

\begin{tabular}{|c|c|}
\hline Dimensions in Slow Tourism & Sub-dimensions \\
\hline Slowness and value of time & $1,2,5,13,14,15,16,17$ \\
\hline Locality and activities at the destination & $4,5,18,19$ \\
\hline Mode of transport and travel experience & $3,6,7,8,9,10,11,20,21,22$ \\
\hline Environmental consciousness & $11,12,23$ \\
\hline \multicolumn{2}{|c|}{$\begin{array}{l}\text { Literatures } \\
\text { Note: (1) Honoré [9]; (2) Krippendorf [11]; (3) Jain and Lyons [12]; (4) Matos [13]; (5) Woehler [14]; (6) } \\
\text { Lumsdon and Page [15]; (7) Ceron and Dubois [16]; (8) Schiefelbusch, Schâfer and Müller [17]; (9) Halsall } \\
\text { [18]; (10) Speakman [19]; (11) Mintel [20]; (12) Dickinson, Robbins and Lumsdon [21]; (13) Virilio [22]; } \\
\text { (14) Andrews [23]; (15) Peeters [24]; (16) Adams [25]; (17) Klein [26]; (18) Pietryowski [27]; (19) Nilsson, } \\
\text { Svard, Widarsson and Wirell [28]; (20) Dann [29]; (21) Elsrud [30]; (22) Barr, Shaw, Coles and Prillwitz } \\
\text { [31], (23) Dolnicar, Crouch and Long [32]. }\end{array}$} \\
\hline
\end{tabular}

According to the framework by Lumsdon and McGrath [1], the mode of transport and travel experience is the most significant dimension in slow tourism [12,15-20,29,30-31]. Slow travel is a journey involving conventional rail transport; without the inclusion of high speed trains [16]. Therefore, the initial concept of using rail travel to facilitate slow tourism can be an additional subdimension to the existing dimension of mode of transport and travel experience. The added dimensions can be demonstrated as per Table 2: 
Table 2. Dimensions in Rail Travel as an Approach for Slow Tourism (Author's own)

\begin{tabular}{|c|c|}
\hline Dimensions in rail travel as an approach for slow tourism & Sub-dimensions \\
\hline Low carbon travel & $1,2,3,4,5,6,7,8,9,10$ \\
\hline Enhancement of travel experience during on-board journey & $11,12,13,14,15,16,17,18,19$ \\
\hline \multicolumn{2}{|c|}{$\begin{array}{l}\text { Literatures } \\
\text { Note: (1) Reis and Jellum [4]; (2) Givoni and Banister [33]; (3) Lumsdon and Dickinson [1]; (4) Wickizer } \\
\text { and Snow [34]; (5) Georgic, Daniel, Roxana, and Stefania [35]; (6) Gardner [36]; (7) Vorster [37]; (8) } \\
\text { Dickinson, Robbins, Filimonau, Hares, and Mika [38]; (9) Willard and Beeton [39]; (10) Markwell, } \\
\text { Fullagar and Wilson [40]; (11) Rhoden [41]; (12) Prideaux [42]; (13) Chen, Shyr, Chen and Li [43]; (14) } \\
\text { Jain and Lyons [12]; (15) Curtin [44]; (16) Lumsdon and McGrath [1]; (17) Watts [45]; (18) Jane [46]; (19) } \\
\text { Sivilevičius, Maskeliūnaitė, Petkevičiené, and Petkevičius [47]. }\end{array}$} \\
\hline
\end{tabular}

In this case, low carbon travel and tourism as mentioned by Vorster [37] is a transformation from the current emissions-centric transportation, accommodation and concerning paradigm in tourism economy to a travel growth that promotes environmental and social conscience. Vorster [37] discusses low carbon land transport, as one of the sub-clusters of low carbon travel in which a shift to mass rail system from cars during travelling can contribute to a 30 per cent reduction of vehicle emission in the next decade.

Furthermore, Givoni and Banister [33] stated that rail transport is possibly 'greener' and environmental-friendly as it is proven that it consumes lesser energy than the other means of transport utilized for long-distance travel. Tourists who chose to travel slowly by utilizing rail would automatically participate in low carbon travelling whether they realize it or not.

Apart from that, rail travel can be experienced as an enhancement of travel especially during the on-board journey. Transport and travel experiences of tourists that are largely remembered, predominantly comprised of visual observation throughout the travelled train route such as the viewing of external objects including landscapes, human and animal life although the transport's interior was also recognized [41]. Train travel can encourage window gazing in which a person may observe harsh environments while being in the comfortness of a train carriage [29]. Therefore, the exterior landscapes, train interior and comfortness can be seen as the indicators for the enhancement of travel experiences if slow tourism is partake by utilizing rail transport.

The importance of finding out the perception of a small number of tourists who undertake rail travel is also because these tourists are aspiring slow tourists. It must be understood that a slow tourist is the advocate for low-impact travel styles and will deliberately avoid flying [35]. Rail transportation can be an alternative mode for the slow tourists to travel rather than flying. During the beginning of the slow tourism appreciation, it is always thought that cycling [40] or hitch-hiking [48] to a destination is the approach of slow mobility.

However, it is mentioned that rail which is the opposing travel mode of flying could also be part of the slow mobility in slow tourism [2]. Therefore, it is suitable for the Malaysian tourism authorities to promote the mobility of slow tourism through the existing rail transport technology in Peninsular Malaysia which is safe and reliable but is fairly considered to be under-used for undertaking tourism in rural towns. 
More importantly, a perception study of slow tourism by rail to rural towns can facilitate towards the success of the cooperative effort between the Ministry of Tourism and Culture Malaysia, the Homestay Association of Malaysia, Keretapi Tanah Melayu Berhad and travel agents in Malaysia and Singapore which was launched in October 2010 [49].The launch was meant to market the Malaysia Rail Tourism packages combining the homestay experience at the rural destination by taking a train, providing tourists the chance to enjoy the scenic Malaysian landscape as part of their holiday experience [49].

This goes hand in hand with the integration of homestay program together with the rail travel packages which is able to display a look into the lives of Malaysian rural community and the traditional communal activities. Currently, the packages are heavily marketed for Singaporeans as the rail travel starts at Tanjong Pagar Railway Station, Singapore, but it could open up a new interest for tourists from other countries to experience the authenticity of rural towns in Peninsular Malaysia. Through this study, the tourism authorities can be provided with an understanding of the perception of tourists that travel on the train to these rural destinations for the future upgrade of the whole railhomestay experiences.

Sustainability is the management of all viable resources according to economic, aesthetic and social needs while preserving the cultural integrity, important eco logical processes and biological diversity [2]. Tourism authorities will be able to adapt sustainability to rural towns by promoting tourism through rail travel and upholding the principle of slowness in travel by enjoying the rail ride without the worry of the extended time being used to pursue rail travel. United Nations of World Tourism Organization stated that the rural community can be sustained when the tourism products act harmoniously with the environment, community and local cultures so that they benefitted out of tourism development rather than suffer because of it [2].

The community will be able to profit from increased tourist arrivals and be employed in tourism jobs without the need of migrating to a bigger city. Moscardo and Pearce [50] suggest that the role of transport in tourism is divided to transport dominating the experience, transport as integrated element of experience, transport as functional link and transport as a significant constraint. This study correlates with that of Lumsdon and Page [15] whom stated the examples of transport commodities that fits the role of transport in tourism. Lumsdon and Page [15] cited intercity rail as the transport example of functional link that facilitates tourism.

However, intercity rail experience itself can prove to be an integrated element of the whole tourism experience as the journey itself focuses on passing by rustic views of rural towns in which it could not be experienced by other modes of transport efficiently in Peninsular Malaysia. Therefore, this study will address the research gap by understanding the perception of tourists who chose to travel with rail in Peninsular Malaysia rather than using other available transport modes.

\section{Research Methodology}

The chosen method to conduct this research is by using qualitative approach in order to achieve deeper understanding of the tourists' and locals' perception to use rail to visit rural towns in Peninsular Malaysia. Qualitative research is chosen because perception studies are usually subjective in nature due to varying opinions among individuals who might or might not be familiar with the research topic. The qualitative methodology can be used to further understand any phenomenon about which little is yet known [51].

They can also be used to gain new perspectives on things which are already known, or things that are hard to be conveyed quantitatively [51]. Slow tourism approach using rail travel to promote rural towns is relatively a new concept of tourism development and very few studies has been conducted on the mind set of locals of a country and international tourists whom are interested to pursue rural tourism in Peninsular Malaysia as the possibility to accept it as a touristic activity. 
The type of qualitative research method adopted for this research will be in depth interviews with selected participants according to the targeted sample which is divided to three groups of ten people. In depth interviews is chosen due to the ability to extract as many information possible from an individual by soliciting their personal views through asking pre-determined open-ended questions. In this research, the sampling method opted is selective sampling which is defined as the selection of people according to the aims of the research using characteristic such as age, status, role in organization and stated ideology as starting points [52]. The researcher will be interviewing thirty individuals of which the first group is ten international tourists travelling on the intercity train to the rural towns from Kuala Lumpur. The second group will be ten Malaysian tourists whom have travelled before on the train to the rural towns for holiday purpose. The third group will be ten Malaysians whom have never travelled before on the train to the rural towns for holiday purpose. In order to find the first and second group sample, the researcher will travel on the day train to selected rural towns in Peninsular Malaysia. The international tourists will be randomly scouted on the train itself through the researchers' observation and their arrival destination while for the local tourists; the researcher will first ask them if they are travelling on the train for the purpose of holiday at the rural towns. Then, the researcher will ask for their permission to be interviewed on the train itself. On the other hand, in order to select the local tourists whom have never use rail to go for holiday at the rural towns, the researcher will do online search through posting the requirements on part time work web portals and provide monetary reward to those who fit the criteria as well as being able to be interviewed one on one on a predetermined time and date.

The qualitative data analysis method will be the documentation of the data obtained from the in depth interviews. Through documentation, data comes from the transcribed text of the interviews recorded in audiotapes [53] in which it contain the reconstructed original comments, observations, and feelings [53]. The next step will be to conduct thematic analysis which is to identify all data that relate to the already classified patterns, expanding the patterns, identify specific and corresponding pattern which are then combined into sub-themes [53]. After obtaining the sub-themes, it is easy to see the emerging patterns and then asking the respondents to give feedback based on the transcribed conversations [53]. The feedback obtained will be further used in the thematic analysis.

\section{Expected Research Findings}

The tourism activities in Malaysia are mainly concentrated in the bigger cities such as Kuala Lumpur, Penang, Melaka and Johor Bahru as well as the popular islands in the west coast and east coast of Peninsular Malaysia. There are other tourism opportunities that can be offered by rural towns should there be more researches conducted on exploring that possibility. Malaysian rural towns do not need major landscape restructuring in order to facilitate tourism but by using the existing facilities and identifying the touristic asset of the towns, it will be sufficient to encourage its growth of tourism. Not to mention, this research would be able to spread the concept of slow tourism approach in travelling by using rail, one of the slower vehicles in order to fully immerse in the Malaysian experience at a reasonable time. It will provide an understanding of travelling at a slower pace for better discovery of cultures and the rural tourism experience.

The conceptualization of this study will be able to facilitate towards the success of Tourism Malaysia's rail tourism packages. Tourism Malaysia has recently launched a number of rail travel packages that combine travelling by Keretapi Tanah Melayu (Malaya Train) to rural towns in peninsular Malaysia with homestay accommodation and participation in cultural activities. The program has been in running for less than two years and it will be interesting to find out the opinions of tourists whom have participated or are interested in the tours. By understanding their perception and satisfaction of the tours, the researcher will be able to identify the success and matters of improvement within the rail travel packages. Rail travel by using slow tourism approach would contribute to Malaysia's pledge towards becoming a sustainable tourism destination. The approach is useful in the long term environment preservation of Malaysian rural towns by encouraging rail travel 
instead of other less environmental-friendly vehicles such as airplane, buses and personal automobiles. Encouragement of traveling by rail to the rural towns will enable improved utilization of the existing rail network and further uplift the travel appeal to rural towns in Peninsular Malaysia.

\section{Conclusion}

Slow tourism is a bench of tourism that has not been widely studied especially in the Asian region. The current literatures of slow tourism mostly concentrate on the definition, characteristics and types of slow tourism rather than the perception of individuals to pursue slow tourism during their holidays. Therefore, there are only a few theories that can be used to provide a theoretical framework to this study. Nevertheless, it is hoped that by conceptualizing this study, it can be a stepping stone to a further interest of slow tourism in Asia. Perception studies of rail travel and the willingness of individuals to adapt slowness in their rural travel experiences will be the major drive of this study. As the proposed methodology will be interviews with the selected individuals, findings will be obtained after analysis of the interviews. The understanding of tourists' perception on choosing a slower transportation such as rail can be detrimental towards the success of applying the slow tourism concept by rail to visit rural towns. This research could also facilitate future studies by applying slow tourism approach in the time taken, cuisine experienced, attraction visited and accommodation chosen.

\section{Acknowledgement}

The funding for this project was made possible through a research grant obtained from the Malaysian Ministry of Education, under the Long Term Research Grant Scheme (LRGS), 2011. Reference no. JPT.S (BPKI) 2000/01/015JId.4 (67).

\section{References}

1. L.M. Lumsdon \& P. McGrath, Developing a conceptual framework for slow travel: a grounded theory approach. Journal of Sustainable Tourism, 19, 3, 265-279 (2011)

2. B.F. Timms \& D. Conway (n.d.). Slow Tourism at the Caribbean's Geographical Margins, (Dodman 2009).

3. A.C. Reis \& C. Jellum. Rail Trail Development: A Conceptual Model for Sustainable Tourism. Tourism Planning \& Development, 9, 2, 133-147 (2012)

4. F.W. Foxworthy. Commercial timber trees of the Malay Peninsula (1927)

5. A. Liu. Tourism in rural areas: Kedah, Malaysia. Tourism Management, 27, 5, 878-889 (2006)

6. S. Heitmann, P. Robinson \& G. Povey. Slow Food, Slow Cities and Slow Tourism. In P. Robinson, S. Heitmann, \& and P. Dieke (Eds.), Research Themes for Touris. UK: CAB International. 114-127 (2011)

7. S. Pink, (2008, September). Mobilising visual ethnography: Making routes, making place and making images. In Forum Qualitative Sozialforschung/Forum: Qualitative Social Research, 9, 3, (2008)

8. C. Honoré. In Praise of Slowness. How a Worldwide movement is Changing the Cult of Speed. San Francisco: HarperCollins (2004)

9. J.E. Dickinson \& L. Lumsdon, L. Slow travel and tourism. Earthscan (2010)

10. J. Krippendorf. The Holiday Makers. London: Heinemann (1984)

11. G. Lyons, J. Jain \& D. Holley. The use of travel time by rail passengers in Great Britain. Transportation Research Part A: Policy and Practice, 41, 107-120 (2007)

12. R. Matos. Can Slow Tourism Bring New life to Alpine Regions?. In K. Weirmair, \& C. Mathies (Eds.), The Tourism and Leisure Industry Shaping the Future. USA: Routledge. 93-104 (2004) 
13. K.K. Woehler. Chapter 5. The Rediscovery of Slowness, or Leisure Time As One's Own and As Self-Aggrandizement?. 83-92 (2004)

14. L. Lumsdon \& S.J. Page. Progress in transport and tourism research: reformulating the transport-tourism interface and future research agendas. Elsevier Science Ltd 1-27 (2004)

15. J.P. Ceron \& G. Dubois. Limits to tourism? A backcasting scenario for sustainable tourism mobility in 2050. Tourism and Hospitality Planning \& Development, 4, 191-209 (2007)

16. M. Schiefelbusch, A. Jain, T. Schafer \&D. Muller. Transport and tourism: The roadmap to integrated planning developing and assessing integrated chains. Journal of Transport Geography, 18, 482-489 (2007)

17. D.A. Halsall. Railway heritage and the tourist gaze: Stoomtram Hoorn-Medemblik. Journal of Transport Geography, 9, 151-160 (2001)

18. C. Speakman. Tourism and transport: Future prospects. Tourism and Hospitality Planning \& Development, 2, 129-137 (2005)

19. Mintel. Slow travel special report. London: Author. N (2009)

20. J.E. Dickinson, D.K. Robbins \& L. Lumsdon. Holiday travel discourses and climate change. Journal of Transport Geography, 18, 482-489 (2010)

21. P. Virilio. La Vitesse. Paris: Éditions Flammarion (1991)

22. C. Andrews. Slow is beautiful: new visions of community, leisure and joie de vivre. New Society Publishers (2006)

23. P. Peeters, P. Mitigating tourism's contribution to climate change - an introduction. In P. Peeters (Ed.), Tourism and climate change mitigation: Methods, greenhouse gas reductions and policies. Breda, The Netherlands: Stichting NHTV Breda. 11-26 (2007)

24. B. Adams. Time. Cambridge: Polity (2004)

25. O. Klein. Social perception of time, distance and high-speed transportation. Time and Society, 13, 245-263 (2004)

26. B. Pietryowski, B. You are what you eat: The social economy of the slow food economy. Review of the Social Economy, 62, 307-321 (2004)

27. J.H. Nilsson, A.C. Svard, A. Widarsson \& T. Wirell (2007, September 27-29). Slow destination marketing in small Italian towns. Paper presented at the 16th Nordic Symposium in Tourism and Hospitality Research, Helsingborg, Sweden (2007)

28. G.M.S. Dann. Travel by train: keeping nostalgia on track. In A.V. Seaton (Ed.), Tourism: The state of the art. Chichester, UK:Wiley. 775-782 (1994)

29. T. Elsrud. Time creation in travelling. Time and Society, 7, 309-334 (1998)

30. S. Barr, G. Shaw, T. Coles \& J. Prillwitz. A holiday is a holiday: Practicing sustainability, home and away. Journal of Transport Geography, 18, 474-481 (2010)

31. S. Dolnicar, G. Crouch \& P. Long. Environmentally friendly tourists: What do they really know about them? Journal of Sustainable Tourism, 16, 197-210 (2009)

32. M. Givoni \& D. Banister. Reinventing the wheel-planning the rail network to meet mobility needs of the 21st century. TSU working paper, Ref. 1036 (2008)

33. B.J. Wickizer \& A. Snow. Rediscovering the Transportation Frontier: Improving Sustainability in the United States Through Passenger Rail. Sustainable Dev. L. \& Pol'y, 11, 12. (2010)

34. G. Georgic, B. Daniel, D.M. Roxana \& B. Stefania (n.d.). Slow Movement as an Extension of Sustainable Development for Tourism Resources : A Romanian Approach, 595-605 (2004)

35. N. Gardner. a manifesto for slow travel, 25(April) (2009)

36. S. Vorster. Travel and tourism ("travelism ") in the low-carbon economy: The role of public policy in accelerating decarbonisation over the next four decades, (October) (2012)

37. J.E. Dickinson, D. Robbins, V. Filimonau, A. Hares \& M. Mika, M. Awareness of Tourism Impacts on Climate Change and the Implications for Travel Practice A Polish Perspective. Journal of Travel Research, 52, 4, 506-519 (2013)

38. P. Willard \& S. Beeton. Low Impact Experiences: Developing Successful Rail Trail Tourism. Tourism Planning \& Development, 9, 1, 5-13 (2012) 
39. S. Fullagar, K. Markwell \& E. Wilson (Eds.). Slow tourism: Experiences and mobilities. Channel View Publications. 54 (2012)

40. S. Rhoden. (CAssociation for European Transport and contributors (2006)

41. B. Prideaux. Tracks to tourism: Queensland rail joins the tourist industry. International Journal of Tourism Research, 1, 2, 73-86 (1999)

42. C. Chen Wei, O.F. Shyr, C. Chen Huan \& T. Li. High Speed Rail Tourism and the Generation Y Market: Any Possibilities?. International Journal Of Science In Society, 3, 4, 71-80 (2012)

43. S. Curtin. Wildlife tourism: the intangible, psychological benefits of human-wildlife encounters. Current Issues in Tourism, 12, 5-6, 451-474 (2009)

44. L. Watts, L. The art and craft of train travel. Social \& Cultural Geography, 9, 6, 711-726 (2008)

45. A. Jane, A. All together onboard. Travel Trade Gazette UK \& Ireland, (3104), 46 (2014)

46. H. Sivilevičius, L. Maskeliūnaite, B. Petkevičienė \& K. Petkevičius. The model of evaluating the criteria, describing the quality of organization and technology of travel by international train. Transport, 27, 3, 307-319 (2012)

47. M. O'Regan. Alternative mobility cultures and the resurgence of hitchhiking. Slow tourism: Experiences and mobilities. Bristol: Channel View, 128-142 (2012)

48. Media Release Malaysia Launches Rail and Homestay. (2010).

49. G. Moscardo \& P.L. Pearce, Chapter 2: Life Cycle, Tourist Motivation and Transport: Some Consequences for the Tourist Experience. In Tourism \& Transport, 29 (2004)

50. M.C. Hoepfl. Choosing qualitative research: A primer for technology education researchers (1997)

51. I.T. Coyne, I. T. Sampling in qualitative research. Purposeful and theoretical sampling; merging or clear boundaries?. Journal of advanced nursing, 26, 3, 623-630 (1997)

52. J. Aronson. A pragmatic view of thematic analysis. The qualitative report, 2, 1, 1-3 (1994) 